\title{
Uso de fatores de crescimento no microagulhamento para tratamento da alopécia androgenética
}

\section{Use of growth factors in microbiology for the treatment of androgenetic alopetics}

Kelle Maria Almeida Lima Alves ${ }^{1}$, Samira Negreiros Brandão², Naia Siqueira ${ }^{3}$

\section{RESUMO}

Nos dias de hoje, a estética vem sendo cada vez mais procurada, por parte dos homens, e alguns procedimentos estão sendo realizados em clínicas e consultórios para 0 tratamento da alopecia androgenética (AAG). A alopécia androgenética é resultado da estimulação dos folículos pilosos por hormônios masculinos (testosterona) que começam a ser produzidos na adolescência. Uma alteração do ciclo folicular, com encurtamento da fase anágena, é responsável pelo processo de miniaturização do pelo. A técnica de microagulhamento se enquadra como um método seguro, rápido e eficaz para tratamentos estéticos seja pela permeação de ativos ou pela estimulação de colágeno e neovascularização. O microagulhamento pode ser associado a fatores de crescimento, com uma importante ação angiogênese, aumentando o processo microcirculatório local, ativando a divisão celular e crescimento de novas células.

Palavras-chave: Microagulhamento. Folículo. Androgenética.

\section{ABSTRACT}

Nowadays, aesthetics have been increasingly sought by men, and some procedures are being performed in clinics and clinics for the treatment of androgenetic alopecia (AAG). Androgenetic alopecia is the result of stimulation of the hair follicles by male hormones (testosterone) that begin to be produced in adolescence. A change in the follicular cycle, with shortening of the anagen phase, is responsible for the process of hair miniaturization. The microneedle technique fits as a safe, fast and effective method for aesthetic treatments either by the permeation of active or the stimulation of collagen and neovascularization. Microaggregation can be associated with growth factors, with an important angiogenesis action, increasing the local microcirculatory process, activating cell division and growth of new cells.
Esteticista. Centro Universitário Luterano de Palmas (CEULPULBRA). Palmas - TO. Brasil.

Especialista em Saúde Estética. Instituto de Excelência em Educação e Saúde (IESS). ). Palmas - TO. Brasil.

E-mail: samira.fisiot@gmail.com

Fisioterapeuta. Centro Universitário Luterano de Palmas (CEULP-ULBRA). ). Palmas - TO. Brasil.

Especialista em Saúde Estética. Instituto de Excelência em Educação e Saúde (IESS). ). Palmas - TO. Brasil.

Biomédica. Professora do Instituto de Excelência em Educação e Saúde (IESS). ). Palmas - TO. Brasil.

Keywords: microneedle. Follicle. Androgenetic.

\section{INTRODUCÃ̃O}

Com a globalização e a competição do mundo atual, a preocupação com a aparência física se torna cada vez mais importante na sociedade mundial. $E$ uma das maiores preocupações é o cabelo. A maior preocupação em relação aos cabelos é quanto a sua queda. Devido a várias causas, nos dias atuais o quadro de queda capilar aumenta progressivamente tanto em homens quanto em mulheres (WEIDER, 2008).

A alopecia androgenética é a forma mais comum de perda de cabelos no gênero masculino em idades mais avançadas, podendo ser observadas em mulheres de uma 
forma menos característica e de mais difícil diagnóstico (MULINAREBRENNER; SOARES, 2009).

O desenvolvimento dessa patologia é dependente da suscetibilidade genética sendo desencadeada pela ação de hormônios andrógenos. Apesar de não ocorrer nenhum dano na saúde física, a alopecia traz consequências emocionais e na autoestima do paciente (FILHO, 2011).

É fundamental para um tratamento correto, o entendimento das fases que ocorrem no desenvolvimento do ciclo normal do crescimento do cabelo, podendo assim amenizar, ou pelo menos, retardar a queda do fio, diminuindo o aparecimento precoce da alopecia. O folículo sofre alterações que caracterizam três fases bem distintas no ciclo de crescimento do fio: a anágena ou de crescimento, a catágena ou de regressão e a telógena ou de repouso (MULINARI-BRENNER; SOARES, 2009).

Existem poucos recursos de tratamento para tal patologia, os fármacos disponíveis para tratamento da alopecia androgenética masculina, apesar de apresentarem bons resultados, observam-se alguns efeitos adversos indesejáveis, devido a isso poucos são os homens que optam por tal tratamento (REBELO, 2015).

O Microagulhamento foi recentemente incluído no arsenal terapêutico da alopecia androgenética devido aos seguintes fatos: libera fatores de crescimento derivados de plaquetas e epidérmicos, possibilita a regeneração através das lesões, ativa célulastronco no bulbo e leva à superexpressão de genes relacionados ao crescimento capilar e fator de crescimento endotelial vascular. A técnica de microagulhamento promove a infusão de medicamentos associados ao procedimento, utilizando o dispositivo com agulhas adequadas que atendam aos princípios adequados de esterilização e descarte de equipamentos (JEONG, $\mathrm{K}$ et al., 2012).

Os fatores de crescimento são proteínas que são capazes de alterar o crescimento, proliferação e a diferenciação celular e atuam como papel importante na estrutura e função da pele (ARNDT; BARROS, 2016).

Quando ocorre uma lesão na pele acontece um processo de reparo, as células que foram lesadas liberam fatores de crescimento. Como o fator de crescimento fibroblástico (FGF), fator de crescimento epidérmico (EGF), fator de crescimento derivado de plaquetas (PDGF), fator de crescimento de transformação (TGF), e a pele passa por tres fases de cicatrização, a inflamação, granulação e remodelamento (OLIVEIRA, 2010). 
Para elaboração deste trabalho foi realizado um levantamento da literatura cientifica presente em artigos eletrônicos sobre o uso de fatores de crescimento no microagulhamento para tratamento da alopécia androgenética.

Foram consultadas as bases de dados PubMed, Scielo, Science direct e International Journal of Trichology, no período compreendido entre maio e setembro 2018, utilizando principalmente as seguintes palavras chaves: Androgenic Alopecia, Hair loss, Microneedling e Growth factor.

Foram selecionados os artigos em língua portuguesa e inglesa sem restrição ao ano e tipo de publicação, citando-as de forma indireta ao longo do texto.

\section{DESENVOLVIMENTO}

O fio de cabelo é definido como uma estrutura que se origina de uma glandula sebácea com um pelo chamado de folículo piloso. O pelo é constituido por uma raiz e uma haste. A raiz é composta por várias camadas de queratina e possui uma extremidade inferior em forma de bulbo que cobre a papila dérmica. A haste é a parte do pelo que se projeta para fora da pele (CIRILLO, 2016).

O desenvolvimento e a multiplicação das células do folículo não são contínuos. Segue um padrão cíclico entre fases de crescimento e de repouso. O folículo sofre alterações que caracterizam três fases no ciclo de crescimento dos pelos: a anágena ou de crescimento, a catágena ou de regressão e a telógena ou de repouso (SOARES, 2009).

A fase anágena é caracterizada por uma grande atividade metabólica e elevada taxa mitótica nas células da matriz do folículo piloso. A fase catágena inicia-se quando o suprimento de células de matriz declina devido ao seu limitado número de divisões celulares, onde as células do folículo entram em involução e apoptose. A fase telógena ocorre quando o folículo entra em um estado de repouso, aproximadamente $10 \%$ dos folículos do couro cabeludo estão nesta fase (ALONSO e FUCHS, 2003).

Alopécia é o termo científico usado para designar a perda parcial ou total, senil ou prematura, temporária ou definitiva, dos pelos ou cabelos. A alopécia androgenética é caracterizada por uma perda progressiva do diâmetro, comprimento, e pigmentação do cabelo e o próprio termo, "androgenética", descreve os dois principais fatores causais deste distúrbio: androgénios e fatores genéticos (REBELO, 2015). 
É o resultado da miniaturização progressiva do folículo piloso e alteração dinâmica dos ciclos. Em cada passagem pelo ciclo, a duração da fase anágena diminui e a fase telógena aumenta. Com a progressão desses ciclos, a fase anágena se torna tão curta que o pelo emergente não alcança a superfície da pele, e o único sinal do folículo é um poro. A miniaturização do pelo é global, afetando toda a estrutura folicular: a papila, a matriz e a haste (MULINARI-BRENNER; SOARES, 2009).

No sexo masculino, a alopecia androgenética inicia-se entre os 20 e 30 anos, sendo sua progressão lenta. Observa-se o prolongamento dos recessos frontais e frontoparietais (entradas) e o afinamento de pêlos do vertex. Alguns casos podem evoluir com ausência total de pelos. No sexo feminino a alopecia androgenética é mais difusa, sendo classificada em 3 graus. No grau I é visível apenas uma leve rarefação do cabelo. No grau Il a densidade dos cabelos diminui de tal forma que é possível enxergar o couro cabeludo. No grau III encontram-se os casos avançados com a calvície já instalada (PAIVA, 2006).

Os hormônios testosterona e seu metabolito dihidrotestosterona (DHT) exercem um papel importante nos eventos da alopecia androgenética por interagir com o receptor nos folículos capilares (SINCLAIR, 2004).

Ao atingir o couro cabeludo, a testosterona sofre ação de uma enzima, a 5-alfaredutase, e é transformada em DHT. Com a ligação da DHT ao receptor andrógeno ocorre uma mudança conformacional no complexo hormônio-receptor formado, gerando uma sinalização para a papila dérmica entrar precocemente em fase catágena, subsequentemente na fase telógena, ocasionando uma modificação no ciclo de crescimento capilar e consequente miniaturização desses folículos pilosos (RANDALL, 2007).

A testosterona e a DHT são os principais androgênios responsáveis pela alopécia androgenética, entretanto a DHT se liga ao receptor de androgênio com potência cinco vezes maior do que a testosterona. Há vários anos a indústria cosmética e estética desenvolve tratamentos para esta patologia, onde visa a rápida recuperação do tecido, para não atrapalhar a rotina do paciente, com técnicas menos invasivas e bons resultados sem efeitos adversos indesejáveis (PEREIRA, 2012).

O intuito do tratamento da alopécia androgenética é diminuir a queda capilar e aumentar a cobertura do couro cabeludo. Técnicas atuais estão sendo utilizadas, principalmente associadas aos cosméticos, facilitando a penetração de ativos. 0 microagulhamento foi incluso recentemente no manejo terapêutico da alopécia androgenética por atuar liberando fatores de crescimento derivados das plaquetas, fatores 
de crescimento epidérmicos, por ativar regeneração através das feridas cutâneas, ativar as células-tronco do bulbo capilar, levar a superexpressão de genes relacionados ao desenvolvimento capilar e fator de crescimento endotelial vascular (CONTIN, 2016).

A técnica de microagulhamento descende da Acupuntura, que faz parte da Medicina Oriental Chinesa. Nos anos 1960, na França, surgiram os primeiros achados da técnica considerada Nappage, que se tratava de pequenas incisões na pele para a administração de fármacos, cujo objetivo era rejuvenescimento facial. Em 2006 elaborou a técnica de indução de colágeno (TIC), que se utilizava de um rolo com agulhas de aço visando melhorar cicatrizes e rugas finas (LIMA, 2015).

Microagulhamento é um método que cria microcanais transdérmicos através da camada de barreira do estrato córneo da pele para aumentar a permeabilidade na pele de fármacos, moléculas pequenas, proteínas e vacinas. Além disso, a administração de drogas através de microagulhas é mais confiável e consistente que as vias orais porque evita a degradação digestiva e o metabolismo do fígado. Além do efeito de liberação da droga, a microagulha pode causar micro lesões na pele, o que induz o processo de estímulo de cicatrização (KIM, 2016).

A introdução da agulha causa um processo inflamatório de cicatrização que possui três fases, a inflamatória, cicatrização e maturação. Na primeira fase, a inflamatória, ocorre a liberação de plaquetas e neutrófilos responsáveis pela liberação de fatores de crescimento com ação sobre os queratinócitos e os fibroblastos. Na segunda fase, a cicatrização, os neutrófilos são substituídos por monócitos, onde ocorre a angiogênese, epitelização e proliferação de fibroblastos, seguidos da produção de colágeno tipo III, elastina, glicoaminoglicanos e proteoglicanos. Os fatores de crescimento dos fibroblastos são secretados pelos monócitos. Depois de cinco dias da fase inflamatória a matriz fibronectina está formada, possibilitando o depósito de colágeno logo abaixo da camada basal da epiderme. Na terceira fase, a maturação, o colágeno tipo III é substituído pelo colágeno tipo I. A intensidade destas reações está intimamente ligada ao tamanho da agulha, de acordo com a injúria provocada no tecido (ARNDT; BOMBACINI, 2016).

O instrumento utilizado para realizar o microagulhamento é o sistema roller, um rolo de polietileno em forma de tambor pequeno recoberto por diversas agulhas finas $(0,1 \mathrm{~mm}$ de diâmetro), feitas de aço inoxidável cirúrgico ou liga de titânio, em diferentes milímetros de comprimento $(0,5$ a 3,0 mm) posicionados paralelamente em várias fileiras, sendo de 190 a 540 agulhas, variando segundo o fabricante. O instrumento é pré-esterilizado por irradiação gama, sendo seu uso único (DODDABALLAPUR, 2009). 
Durante o procedimento de microagulhamento, o rolo é passado algumas vezes sobre a pele com movimentos de vai e vem, que devem guiar-se por padrão uniforme em toda a área tratada. Para isso, cerca de 10 passadas nas direções horizontais, verticais e diagonais, formando quatro cruzamentos das áreas de rolagem. Ocorre um quadro de hiperemia até um leve sangramento, sendo espontaneamente controlado (LIMA, 2013).

Os microcanais formados pelo microagulhamento favorecem ao aumento da permeação de moléculas hidrofílicas e macromoléculas das formulações aplicadas, aumentando a permeação dos ativos em até $80 \%$. Os fatores de crescimento humanos (HGF, sigla em ingles para Human Growth Factors) são citocinas, um grupo de polipeptídeos secretados por várias moléculas reguladoras do nosso organismo. Atuam como mediadores na maturação celular e responsáveis pelos processos de reparação de danos celulares. Tem ação importante de angiogênese, aumentando o processo microcirculatório local e ativando vários grupos celulares na integração e vitalidade dos tecidos (BOMBACINI, 2016).

Os Fatores de Crescimento e seus Peptídeos são obtidos por biotecnologia pela técnica de produção de proteínas recombinantes - a mesma técnica adotada na produção de vacinas, antibióticos e enzimas. Um sequenciamento de aminoácidos obtidos do DNA humano é inoculado na bactéria Escherichia coli, que, por processo fermentativo, produz os Fatores de Crescimento. Após o processo de isolamento e purificação, os Fatores de Crescimento e seus Peptídeos são nanoencapsulados a fim de viabilizar a permeação cutânea (biodisponibilidade) e proteção contra proteases endógenas (VANZIN, 2011).

A influência dos fatores de crescimento no ciclo capilar, não se baseia exclusivamente na vasodilatação e nutrição do tecido, sabe-se que estas substâncias são responsáveis por formação de novos folículos capilares com abundante deposição de matriz extracelular: essencial para o crescimento e permanência do novo fio de cabelo; aumento do tamanho do bulbo capilar dos folículos já existentes - ação fortificante; acelera o crescimento capilar, através do aumento da mitose folicular - interessante não apenas para quem sofre da queda capilar como reclama da demora do crescimento dos cabelos; angiogênese capilar: surgimento de novos capilares sanguíneos envolvendo o novo folículo - essencial para a nutrição e vitalidade dos cabelos; inibir a enzima 5-alfa redutase -responsável por aumentar os níveis de DHT(dihidrotestosterona) hormônio que atrofia o folículo capilar e causador da alopecia androgenética (VANZIN, 2011).

O fator de crescimento fibroblástico ácido (AFGF) é conhecido pelo efeito sobre replicação de células endoteliais e neovascularização. O AFGF é encontrado armazenado 
na matriz extracelular. Apresentam propriedades angiogênicas: formação de vasos sanguíneos a partir de vasos preexistentes. Quimiotáticos: atraem e repelem células; e mitogênico: proliferação celular; sendo possível para vários tipos de células como fibroblastos e células endoteliais (BOMBACINI, 2016).

Aumenta a circulação sanguínea do couro cabeludo; promove a revitalização dos folículos capilares; estimula o crescimento capilar e inibe sua despigmentação. $O$ fator de crescimento do endotélio vascular (VEGF), em Inglês VEGF (vascular endotelial growth factor), atua basicamente no ciclo germinativo capilar, é considerado um importante mediador de angiogênese que atua diretamente e exclusivamente no endotélio vascular. In vitro o VEGF é capaz de promover o crescimento de células endoteliais vasculares a partir de artérias, veias e vasos linfáticos e impede a apoptose endotelial induzida por privação de nutrientes. Tanto in vitro quanto in vivo o VEGF também é um fator de sobrevivência para o endotélio (BOMBACINI, 2016).

Os peptídeos de Cobre (Copper Peptídeo®) são fragmentos de fatores de crescimento que agem na diferenciação celular que são capazes de atuar no processo de cicatrização devido à proliferação de fibroblastos dérmicos, estimula a produção da matriz extracelular, a angiôgenese e a proliferação do folículo piloso, além de elevar o folículo endoltelial vascular (VEGF). Ainda tem ação de inibir a enzima 5-alfa redutase que é responsável por reduzir a testosterona em diidrotestosterona (DHT), auxiliando na revitalização do folículo capilar, aumentando a circulação sanguínea podendo reverter à atrofia folicular induzida pela DHT (VANZIN, 2011).

O Fator de Crescimento Fibroblástico básico (bFGF) é produzido por queratinócitos, células do folículo piloso, glândulas sudoríparas e salivares e pelas células endoteliais. Produz aumento da proliferação de células endoteliais, capilares, queratinócitos, melanócitos e astrócitos. Os fibroblastos são ativados, tornando-se alongados, e há modulação da produção de colágeno. Melhora a circulação periférica, sendo indicado para desordens capilares (RIEGER, 2017).

O Fator de Crescimento Insulínico (IGF) é produzido por queratinócitos, fibroblastos e hepatócitos, atua sobre células que possuem receptores específicos, queratinócitos da camada basal, melanócitos, fibroblastos e células da matriz dos pêlos. Estimula os folículos capilares a produzirem um cabelo mais denso e forte (RIEGER, 2017). 


\section{CONSIDERAÇOES FINAIS}

Os cabelos exercem um papel de extrema importância no ser humano, sendo considerado um fator de beleza. A queda capilar pode influenciar negativamente a autoestima do paciente.

A alopecia androgenética é uma manifestação fisiológica resultado da estimulação dos folículos pilosos provocados por hormônios masculinos, como a testosterona, ocasionando a miniaturização folicular, ou seja, a diminuição progressiva dos fios de cabelo a cada ciclo de crescimento, fazendo com que nasçam cada vez menores e mais finos.

O presente estudo estabeleceu uma relação entre o uso dos fatores de crescimento no microagulhamento e sua ação para a alopécia androgenética, observando resultados satisfatórios, tanto pelo efeito do microagulhamento, quanto pelo aumento na absorção dos fatores de crescimento pela formação dos microcanais.

De acordo com a revisão bibliográfica, notou-se uma boa resposta terapeutica, quando indicada, ocasionando um aumento do crescimento capilar e diminuição da queda. O uso do microagulhamento associado a fatores de crescimento mostrou uma alternativa viável para tratar a alopécia androgenética.

\section{REFERÉNCIAS}

ALONSO, Laura; FUCHS, Elaine. The hair cycle. Journal of Cell Science 119: 391- 393, 2006.

ARNDT, Helena Renata; BARROS, Tamires do R. F de. Estudo sobre microagulhamento associado com fator de crescimento para alopécia androgenética. p. 1-11, 2016.

BOMBACINI, Adrieli Soares; LUBI, Neiva. Estudo de caso: Microagulhamento e fator de crescimento \& peptideo associados no tratamento de alopécia androgenética. 2016, 20f. Monografia de conclusão de curso de Tecnologia em Estética e Cosmética. Universidade Tuiti do Paraná, Curitiba, 2016.

CAVALCANTI, C. P. Protocolos de tratamento da alopécia: Uma revisão. 2015. 30f. Trabalho de Conclusão de Curso (Graduação em Farmácia) - Universidade Estadual da Paraíba, Campina Grande, 2015.

CIRILLO, Marilene Gomes da Silva. A terapia do microagulhamento no tratamento da alopécia androgenética. $13 \mathrm{f}$. Monografia de Pós-graduação MBA em Tricologia Coméstica e Terapia Capilar. Faculdade Faserra, Manaus, 2016. 
CONTIN, Letícia Arsie. Male androgenetic alopecia treated with microneedling alone or associated with injectable minoxidil by microinfusion of drugs into the skin. Surg Cosmet Dermatol 2016; 8(2):158-61, São Paulo, 2016.

DODDABALLAPUR, Satish. Micronneding With Dermaroller. Journal of Cutaneus and Aesthetic Surgery. v.2, n.2, p.110-111, 2009.

FILHO, Cesar Borges Machado. Alopécia Androgenética masculina: revisão e atualização em tratamentos. Curitiba, 2011.

JEONG, K. et al. Repeated microneedle stimulation induce the enhanced

expression of hair-growth-related genes. Int J Trichology, v. 4, n. 2, p. 117-30,

2012.

KIM, Yoon Seob et al. Repeated Microneedle Stimulation Induces Enhanced Hair

Growth in a Murine Model. Annals of Dermatology, 2016, 28.5: 586-592.

LIMA, Emerson Vasconcelos de Andrade Lima; LIMA,Mariana de Andrade; TAKANO,

Daniela. Microagulhamento: estudo experimental e classificação da injúria

provocada. Surgical \& Cosmetic Dermatology, Rio de Janeiro, v. 5, n. 2, p. 110-114, abr./jun. 2013.

LIMA, Angélica Aparecida; SOUZA, Thaís Helena; GRIGNOLI, Laura Cristina Esquisatto. Os benefícios do microagulhamento no tratamento de disfunções estéticas. Revista Científica da FHO-UNIARARAS, v. 3, n. 1, 2015.

MULINARI-BRENNER, Fabiane; SOARES, Ivy Faigle. Alopécia androgenética masculina: uma atualização. Revista Ciências Medicas, volume 18, número 3: 153- 161. Campinas, 2009.

OLIVEIRA, Letícia Peres. $O$ uso de fatores de crescimento em cosméticos para rejuvenescimento da pele. Porto Alegre, 2010.

PAIVA, Linda Mary Gouget; BOGGIO, Ricardo Frota; PRADO, Juan Carlos; CARLUCCI, Adolfo Ribeiro. Protocolo para tratamento da alopecia androgenética.

Instituto Brasileiro de Pesquisa e Ensino - IBRAPE, São Paulo, 2006 PEREIRA, Carlos Manuel; AGUIAR, Hamilton Azevedo; FRANÇA, Ana Julia Van

Borell Du Varney; SILVA, Daniela. Princípios ativos cosméticos utilizados no tratamento da alopécia. Universidade do Vale do Itajaí, Santa Catarina, 2012.

RANDALL, Valerie Anne. Hormonal regulation of hair follicles exhibits a biological paradox. Seminars In Cell \& Developmental Biology, v. 18, n. 2, p. 274- 285, 2007.

REBELO, Ana Santos. Novas estratégeas para tratamento da alopécia. Dissertação de Mestrado Integrado em Ciências Farmacêuticas apresentada na Universidade Lusófona de Humanidades e Tecnologias/Escola de Ciências e Tecnologias da Saúde. Lisboa, 2015.

RIEGER, Cristina da Costa; GERMANO, Sandro; OLIVEIRA, Silvia Patrícia. O uso de 
fatores de crescimento em cosméticos. Monografia de conclusão de curso de Tecnologia em Estética e Imagem Pessoal da Universidade Tuiuti do Paraná, 2017.

SINCLAIR, Rodney D. Male androgenetic alopecia. The Journal of Men's Health \& Gender, v. 1, n. 4, p. 319-327, 2004

SANTANA, Juliana Viana; LOPES, Valéria Marques; SANTOS, Juliana Amorim Borba. Relação entre Estresse e Alopercia Androgenética: Uma Revisão da Literatura. Id on Line - Revista Multidisciplinar e de Psicologia. V.11, N. 35. abril, 2017.

VANZIN, Sara Bentler. O uso de fatores de crescimento e seus peptídeos no tratamento de alopécia e crescimento de cílios e sobrancelhas. PharmaSpecial Especialidades Químicas e Farmacêuticas, 2011. 